\title{
REGIONAL INCOME CONVERGENCE IN PORTUGAL (1991-2002)
}

\author{
Gertrudes Saúde Guerreiro
}

\begin{abstract}
Does the standard of living vary from region to region in Portugal and are spatial units in Portugal converging in income? We observe spatial error dependence between municipalities and estimate spatial econometric models to test convergence. For conditional convergence we conclude that primary sector employment, activity rate, and percentage of active population with higher education are important to distinguish the "steady state" of the regional economies, reflecting the labor market at regional level.
\end{abstract}

Keywords: Income distribution; regional inequality; regional convergence; spatial econometrics

JEL classifications: C21; E25; R12

Economic Well-Being and Inequality: Papers from the Fifth ECINEQ Meeting

Research on Economic Inequality, Volume 22, 351-381

Copyright $(\mathcal{C} 2014$ by Emerald Group Publishing Limited

All rights of reproduction in any form reserved

ISSN: 1049-2585/doi:10.1108/S1049-258520140000022011 